\title{
EFFECT OF PH AND ANION INTERFERENCES ON DETERMINATION OF ORTHOPHOSPHATE SPECIATION BY DIFFUSIVE GRADIENT IN THIN FILM (DGT) TECHNIQUE
}

\author{
Askal Maimulyanti ${ }^{1 *}$, Budiawan ${ }^{1}$, Asep Saefumillah ${ }^{1}$, and Heny Suseno ${ }^{2}$ \\ ${ }^{1}$ Department of Chemistry, Universitas Indonesia, Depok, 16424, Indonesia \\ ${ }^{2}$ Marine Radioecology Group, Center for Radiation Safety Technology and Metrology, National \\ Nuclear Energy Agency, Jakarta, 12070, Indonesia \\ *E-mail : askal_m@yahoo.com
}

\begin{abstract}
The diffusive gradient in thin film (DGT) is an analytical method on separation and determination of phosphate. The surface analysis of gel was used in the scanning electron microscopy (SEM) that show the chemical and physical interaction in diffuse gel and oxide gel. The response of DGT device in speciation of phosphorus as $\mathrm{H}_{2} \mathrm{PO}_{4}{ }^{-}, \mathrm{HPO}_{4}{ }^{2-}$ and $\mathrm{PO}_{4}{ }^{3-}$ showed a linear correlation between concentration and accumulation of phosphate with the concentration of $0.2-1.0 \mathrm{mgL}^{-1}$. Species of $\mathrm{H}_{2} \mathrm{PO}_{4}^{-}$give a linear correlation of 0.9792 with regression linear at $\mathrm{y}=9.8825 \mathrm{x}-$ 0.0503. The $\mathrm{HPO}_{4}{ }^{2-}$ give a linear correlation of 0.8872 with regression linear at $\mathrm{y}=7.2143 \mathrm{x}-0.7545$. The species of $\mathrm{PO}_{4}{ }^{3-}$ give a linear correlation of 0.9769 with regression linear at $\mathrm{y}=7.5558 \mathrm{x}-0.1828$. The phosphorus accumulation from different speciation showed $\mathrm{H}_{2} \mathrm{PO}_{4}{ }^{-}>\mathrm{PO}_{4}{ }^{3-}>\mathrm{HPO}_{4}{ }^{2}$ with accumulation was $9.6525 \mu \mathrm{g}, 7.1589$ $\mu \mathrm{g}$, and $6.8783 \mu \mathrm{g}$, respectively. The DGT can response of phosphate with various $\mathrm{pH}$ at 2-12 and showed the species of phosphate as $\mathrm{H}_{2} \mathrm{PO}_{4}{ }^{-}, \mathrm{HPO}_{4}{ }^{2-}$ and $\mathrm{PO}_{4}{ }^{3-}$. The optimum response show at the $\mathrm{pH}$ of 4 that shows the species of $\mathrm{H}_{2} \mathrm{PO}_{4}{ }^{-}$. Anion interference was studied in this research including $\mathrm{SO}_{4}{ }^{2-}, \mathrm{NO}_{3}{ }^{-}$and $\mathrm{CO}_{3}{ }^{2-}$. Effect of anion sulfate, nitrate and carbonate can reduce of phosphate accumulation in DGT device in the range of anion concentration from 0.05 to $0.25 \mathrm{mgL}^{-1}$. The interferences of $\mathrm{NO}_{3}{ }^{-}, \mathrm{SO}_{4}{ }^{2-}, \mathrm{CO}_{3}{ }^{2-}$ at $0.25 \mathrm{mgL}^{-1}$ can reduce of phosphate accumulation with the efficiency of $64.64 \%, 25.10 \%$, and $7.57 \%$, respectively. $\mathrm{The}^{-}$effect of $\mathrm{NO}_{3}{ }^{-}>$ $\mathrm{SO}_{4}{ }^{2-}>\mathrm{CO}_{3}{ }^{2-}$ in the accumulation of phosphate in the binding gel of DGT unit.
\end{abstract}

Keywords: orthophosphate, DGT, speciation, $\mathrm{pH}$, anion interferences

(C) RASĀYAN. All rights reserved

\section{INTRODUCTION}

Phosphorus $(\mathrm{P})$ is the limiting nutrient for organism's growth in aquatic system and important nutrition to control eutrophication ${ }^{1}$. The phosphorus was analyzed as a phosphate solution. Monitoring phosphate concentration is very important to prevent and control eutrophication. The effect of eutrophication is rooted mainly in ecological impacts as decrease species biodiversity and abundance ${ }^{2}$. The speciation of orthophosphate in the aquatic environment as $\mathrm{PO}_{4}{ }^{3-}, \mathrm{HPO}_{4}{ }^{2-}$, and $\mathrm{H}_{2} \mathrm{PO}_{4}{ }^{-}$and it available for the organism in aquatic sistem ${ }^{3}$. There are some of the methods for determination of phosphate such as colorimetric (CM) methods with spectrophotometric ${ }^{4}$, ion chromatography (IC) $)^{5}$, high-performance liquid chromatography (HPLC) ${ }^{6}$, and inductively coupled plasma (ICP) technique. The detected of phosphorus is usually as orthophosphate ${ }^{7}$.

The new method was developed for the determination of the labile phosphorus with the diffusive gradient in thin film (DGT). DGT is the method based on the diffusive of the analyte through the diffusive layer ${ }^{8}$. The analyte was diffused to diffusive gel and bonded in oxide gel. The concentration and accumulation of analyte in the binding gel were assumed equivalent with the analyte through the diffusive layer ${ }^{9}$. The concentration of analyte was calculated using Fick's first law of diffusion ${ }^{10}$. The binding agents have been used with DGT method to measurement of trace metal ${ }^{11}$, sulfide ${ }^{12,13}$, mercury ${ }^{14,15}$, radionuclide ${ }^{16,17}$, phosphate. ${ }^{18-20}$ The schematic of the DGT device can be shown in Fig.-1.

Rasayan J. Chem., 11(3), 1222-1228(2018)

http://dx.doi.org/10.31788/RJC.2018.1133057

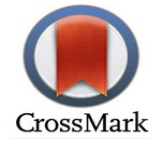




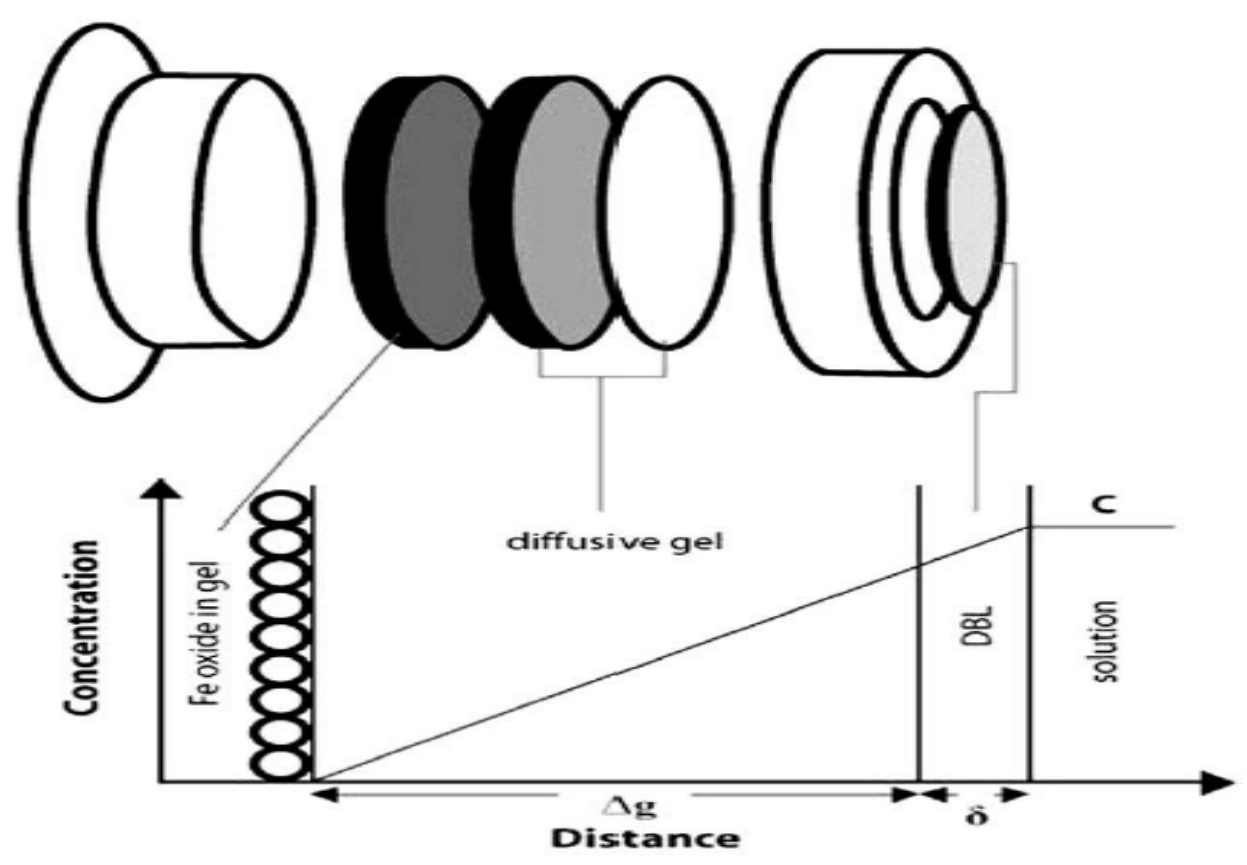

Fig.-1: The Schematic Diagram for Concentration Gradients induced by DGT ${ }^{12}$

The concentration of phosphate (Ce) was measured by spectrophotometric. The mass accumulation (M) of phosphate accumulated in the binding gel can be calculated using the equation of $M=C_{e}\left(V_{\text {gel }}+V_{\text {acid }}\right)$. The study about phosphorus with DGT technique developed in binding agent ${ }^{18}$ and application of DGT technique for phosphorus analysis in the environment such as water ${ }^{3,10,21}$, sediment $^{2,3,22}$ and soil $^{20,23,24}$. A large amount of DGT technique was applicated in environment science and limited study about chemical interaction and speciation of phosphate in DGT technique. The interference has been studied in phosphate analysis for chloride and sulfate ions that indicated there is no effect to binding gel ${ }^{25}$. In the past, the study only described of dissolved phosphate that measured in DGT technique without any explained of the speciation of phosphate.

The purpose of this paper was to study the influence of $\mathrm{pH}$ and anionic interferences on the determination of orthophosphate speciation by using DGT. The performance of the quantitative method used to determine phosphorus speciation. The parameters of phosphate species concentration, $\mathrm{pH}$, and anionic interferences were evaluated in this study.

\section{Material and Methods}

\section{EXPERIMENTAL}

All plastic ware was washed in $5 \%$ of $\mathrm{HNO}_{3}$ and then thoroughly rinsed with deionized water before used. The phosphorus solution was prepared by dissolution of $\mathrm{KH}_{2} \mathrm{PO}_{4}$ in deionized water. DGT device was purchased from DGT Research Ltd.

\section{General Procedure}

The characterization of the surface from binding gel and oxide gel were analyzed scanning electron microscope (SEM). Assembling of DGT device with the binding layer containing ferrihydrite was prepared in this experiment. The DGT device with $2 \mathrm{~cm}$ diameter consisting of cellulose nitrate, polyacrylamide hydrogel, and ferrihydrite as the binding gel. The effect of phosphate speciation used solution $\mathrm{H}_{2} \mathrm{PO}_{4}{ }^{-}, \mathrm{HPO}_{4}{ }^{2-}$, and $\mathrm{PO}_{4}{ }^{3-}$ with the concentration of $\mathrm{P}$ from 0.2 to $1.0 \mathrm{mgL}^{-1}$. The DGT unit was deployed in $250 \mathrm{~mL}$ solution for 24 hours at the room temperature. Phosphate was removed, eluted and the amount of $\mathrm{P}$ in solution was measured. Effect of $\mathrm{pH}$ to uptake by ferrihydrite in DGT unit with deployed it in $250 \mathrm{~mL}$ solution of $\mathrm{P}(0.2 \mathrm{mg} / \mathrm{L})$ at variation $\mathrm{pH}(2-12)$ for deployment of 24 hours at the room temperature. Phosphate was removed, eluted and the amount of $\mathrm{P}$ in solution was measured. The 


\section{RASĀYAN J. Chem.}

Vol. 11 | No. 3 |1222 - 1228 | July - September | 2018

interfering matrix was studied with a phosphorus solution that contains sulfate, nitrate and carbonate ions. Concentration of $\mathrm{P}$ was $0.5 \mathrm{mgL}^{-1}$ and the anion concentration was 0.05 to $0.25 \mathrm{mgL}^{-1}$. Phosphate in the binding gel was eluted by acid and determination by the spectrophotometric method.

\section{RESULTS AND DISCUSSION}

The surface structure of the diffusive gel was studied by scanning electron microscopy (SEM) and the result can be shown in Fig.-2.
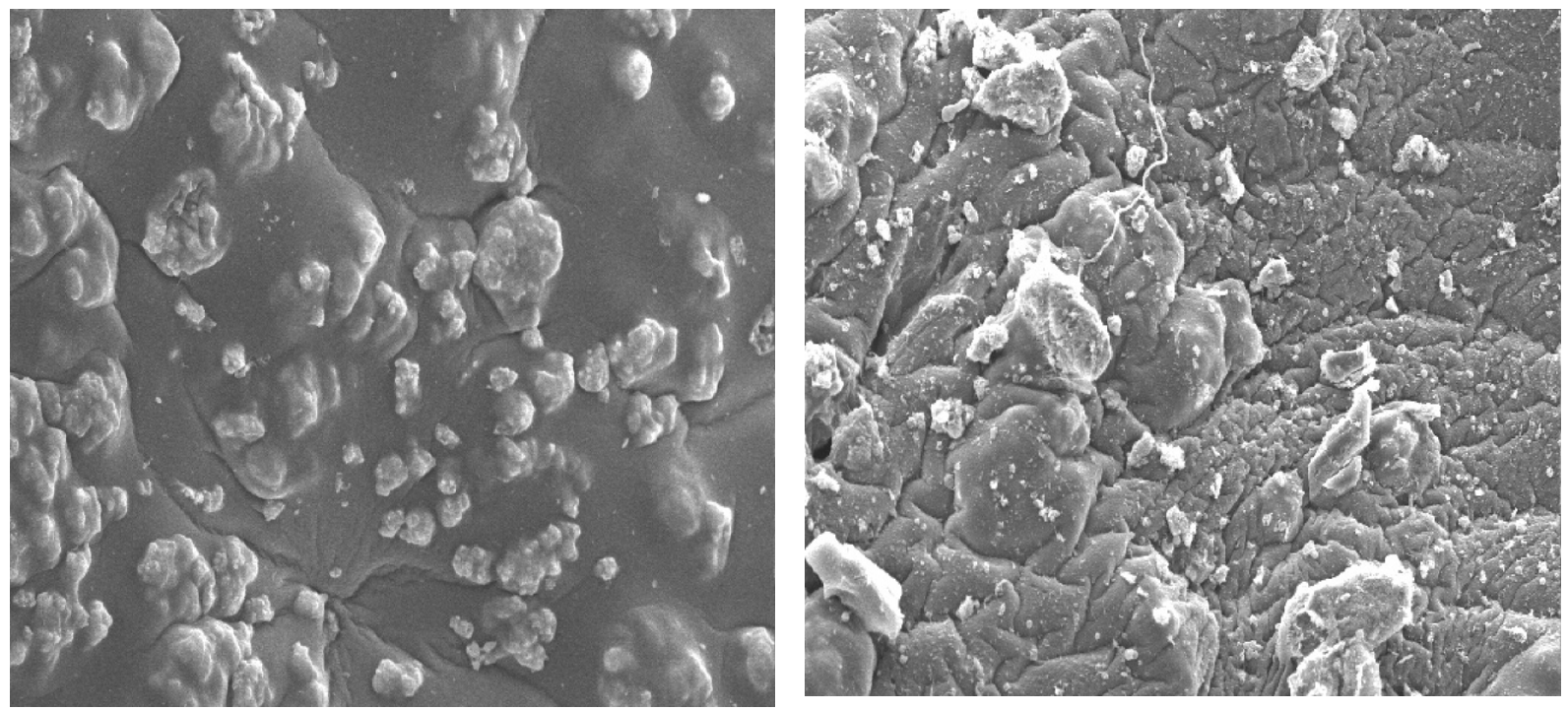

Fig.-2: Scanning Electron Microscopy of Binding Gel before and After Adsorption (500x)

Figure-2 shows the structure of binding gel before and after adsorption of phosphate. The surface morphology of gels was different from each other that indicated chemical and /or physical interaction on the surface of the gel. The mean size of surface cavities was measured on the image and size from the binding gel was $5.73 \times 3.82$ micron. After the adsorption process on the surface of the binding gel, it shows the adsorption of phosphorus has occurred on the surface of ferrihydrite.

Table-1: The Accumulation of Phosphate in Different of Speciation

\begin{tabular}{c|c|c|c}
\hline Concentration of $\mathrm{P}\left(\mathrm{mgL}^{-}\right)$ & \multicolumn{3}{|c}{ Accumulation of Phosphate $(\mu \mathrm{g})$} \\
\cline { 2 - 4 } & $\mathrm{H}_{2} \mathrm{PO}_{4}{ }^{-}$ & $\mathrm{HPO}_{4}{ }^{-}$ & $\mathrm{PO}_{4}{ }^{3-}$ \\
\hline 0.2 & $2.1431 \pm 0.18$ & $0.8242 \pm 0.21$ & $1.0150 \pm 0.11$ \\
\hline 0.4 & $3.0101 \pm 0.14$ & $1.4021 \pm 0.11$ & $2.4458 \pm 0.91$ \\
\hline 0.6 & $6.6327 \pm 1.15$ & $2.0249 \pm 0.28$ & $5.1333 \pm 0.08$ \\
\hline 0.8 & $7.9072 \pm 0.32$ & $5.9862 \pm 0.45$ & $5.8179 \pm 0.15$ \\
\hline 1.0 & $9.6525 \pm 0.69$ & $6.8783 \pm 0.26$ & $7.1589 \pm 0.07$ \\
\hline
\end{tabular}

DGT technique was used to measure speciation of phosphate such as $\mathrm{H}_{2} \mathrm{PO}_{4}{ }^{-}, \mathrm{HPO}_{4}{ }^{2-}$ and $\mathrm{PO}_{4}{ }^{3}$. Based on Fig.-3. showed the different species of orthophosphate gave the different response to the DGT device on phosphorus accumulation. The species of $\mathrm{H}_{2} \mathrm{PO}_{4}$ is the highest sensitivity from the others. The response of DGT unit in speciation of phosphorus as $\mathrm{H}_{2} \mathrm{PO}_{4}{ }^{-}, \mathrm{HPO}_{4}{ }^{2-}$ and $\mathrm{PO}_{4}{ }^{3-}$ showed a linear correlation between concentration and accumulation of phosphorus with the concentration of $0.2-1.0 \mathrm{mg} / \mathrm{L}$. Species of $\mathrm{H}_{2} \mathrm{PO}_{4}$ - give a linear correlation of 0.9792 with linear regression at $\mathrm{y}=9.8825 \mathrm{x}-0.0503$. The range of phosphorus accumulation is from $2.1431 \mu \mathrm{g}$ to $9.6525 \mu \mathrm{g}$. The $\mathrm{HPO}_{4}{ }^{2-}$ give a linear correlation of 0.8872 with linear regression at $y=7.2143 \mathrm{x}-0.7545$. The range of phosphorus accumulation is from $0.8242 \mu \mathrm{g}$ to $6.8783 \mu \mathrm{g}$. The species of $\mathrm{PO}_{4}{ }^{3-}$ give a linear correlation of 0.9769 with linear regression at $\mathrm{y}=7.5558 \mathrm{x}$ - 0.1828. The range of phosphorus accumulation is from $1.0150 \mu \mathrm{g}$ to $7.1589 \mu \mathrm{g}$. The phosphorus 
RASĀYAN J. Chem.

Vol. 11 | No. 3 |1222 - 1228 | July - September | 2018

accumulation from different speciation showed $\mathrm{H}_{2} \mathrm{PO}_{4}{ }^{-}>\mathrm{PO}_{4}{ }^{3-}>\mathrm{HPO}_{4}{ }^{2-}$ with accumulation was 9.6525 $\mu \mathrm{g}, 7.1589 \mu \mathrm{g}$, and $6.8783 \mu \mathrm{g}$, respectively.

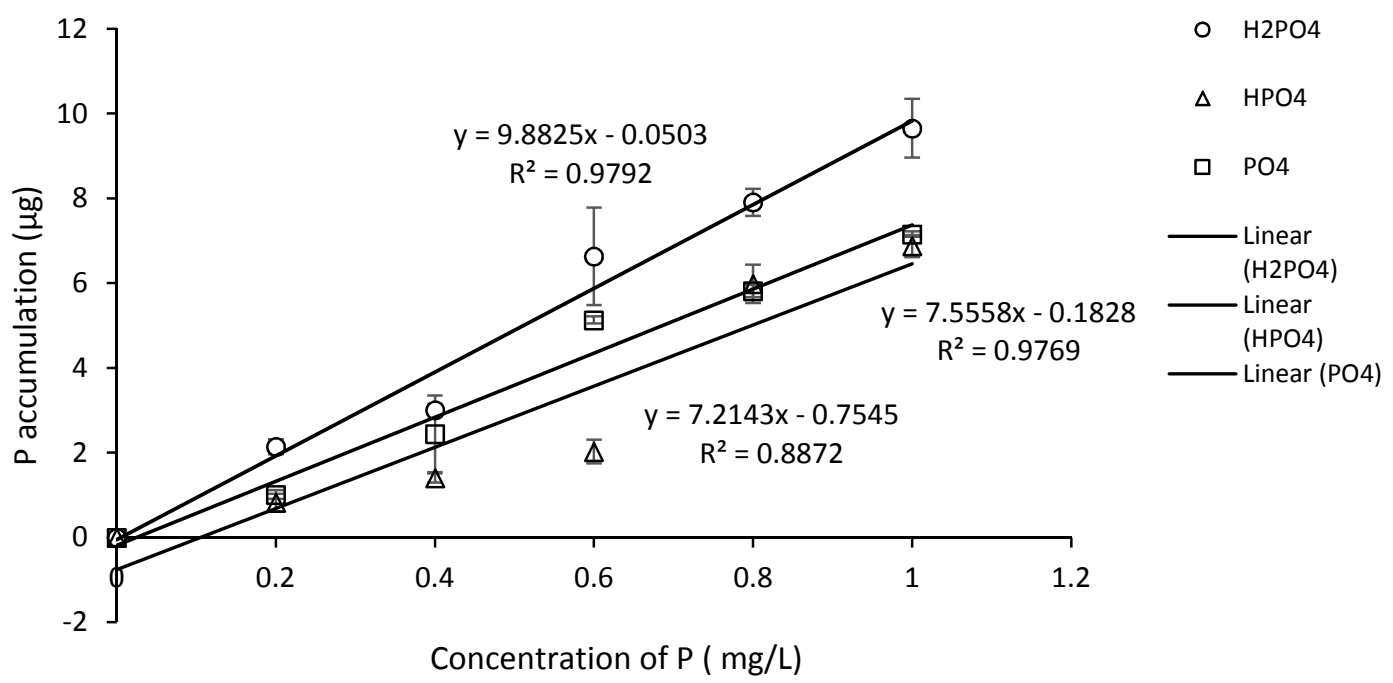

Fig.-3: Speciation of Phosphate on the Accumulation of P in DGT Device

Table-2: Effect of pH on DGT Device

\begin{tabular}{c|c}
\hline $\mathrm{pH}$ & $\begin{array}{c}\text { Phosphate Accumulation } \\
(\mu \mathrm{g})\end{array}$ \\
\hline 2 & $1.6820 \pm 0.11$ \\
\hline 3 & $1.5829 \pm 0.06$ \\
\hline 4 & $1.9189 \pm 0.03$ \\
\hline 5 & $1.5113 \pm 0.03$ \\
\hline 6 & $1.3296 \pm 0.08$ \\
\hline 7 & $1.4287 \pm 0.07$ \\
\hline 8 & $1.5168 \pm 0.04$ \\
\hline 9 & $1.6435 \pm 0.04$ \\
\hline 10 & $1.6215 \pm 0.01$ \\
\hline 11 & $1.9079 \pm 0.09$ \\
\hline 12 & $1.7922 \pm 0.08$ \\
\hline
\end{tabular}

The effect of $\mathrm{pH}$ on the accumulation of phosphate in the DGT device was studied by measured the phosphate concentration before and after deployment. In Fig.-4 shows the optimum accumulation of orthophosphate at $\mathrm{pH} 4$ that indicated the species of $\mathrm{H}_{2} \mathrm{PO}_{4}{ }^{-}$is dominant in DGT unit. The orthophosphate indicated the speciation of $\mathrm{H}_{2} \mathrm{PO}_{4}{ }^{2-}, \mathrm{HPO}_{4}{ }^{-}$, and $\mathrm{PO}_{4}{ }^{3-}$ at $\mathrm{pH}$ range 2-12. However, there is no simple relation between $\mathrm{P}$ speciation in solution and its uptake by ferrihydrite. $\mathrm{P}$ uptake is also related to the chemical properties of oxide gel itself. At low $\mathrm{pH}, \mathrm{H}^{+}$is competing with $\mathrm{P}$ for ferrihydrite site on oxide gel. At $\mathrm{pH}$ range 2-12, ferrihydrite has high affinity to accumulate phosphorous.

The species of phosphorus in solution change according to $\mathrm{pH}$. Therefore in the $\mathrm{pH}$ range maintained in the aquaponics system, phosphorus is mostly present in the form $\mathrm{H}_{2} \mathrm{PO}_{4}^{-}$while $\mathrm{H}_{3} \mathrm{PO}_{4}$ and $\mathrm{HPO}_{4}{ }^{2-}$ have lower activities ${ }^{26}$. The speciation of $\mathrm{H}_{2} \mathrm{PO}_{4}^{-}$was occurred at $\mathrm{pH} 2-7, \mathrm{HPO}_{4}{ }^{2-}$ at the $\mathrm{pH} 7-11$ and the $\mathrm{PO}_{4}{ }^{3-}$ at the $\mathrm{pH}$ more than 12 in the solution ${ }^{27}$.

Effect of diffusive and uptake at binding gel in DGT device was studied with anion interferences. Sulfate, nitrate and carbonate ion were added to phosphorus solution with the range of concentration from 0.05 to $0.25 \mathrm{mgL}^{-1}$ and used phosphorus $0.5 \mathrm{mgL}^{-1}$. The advantages of DGT included a continual time-integrated response to the analyte in solution, the concentration of the phosphate species in the binding layer while interfering matrix component is diluted. The interference effect of sulfate, carbonate, and nitrate on the DGT uptake was investigated. The DGT method with interference $\mathrm{NO}_{3}{ }^{-}, \mathrm{SO}_{4}{ }^{2-}$ and $\mathrm{CO}_{3}{ }^{2-}$ can influence of 
RASĀYAN J. Chem.

Vol. 11 | No. 3 |1222 - 1228 | July - September | 2018

phosphate accumulation in the binding gel. Phosphorus sorption is affected by increasing of anionic concentration up to $0.25 \mathrm{mg} / \mathrm{l}$.

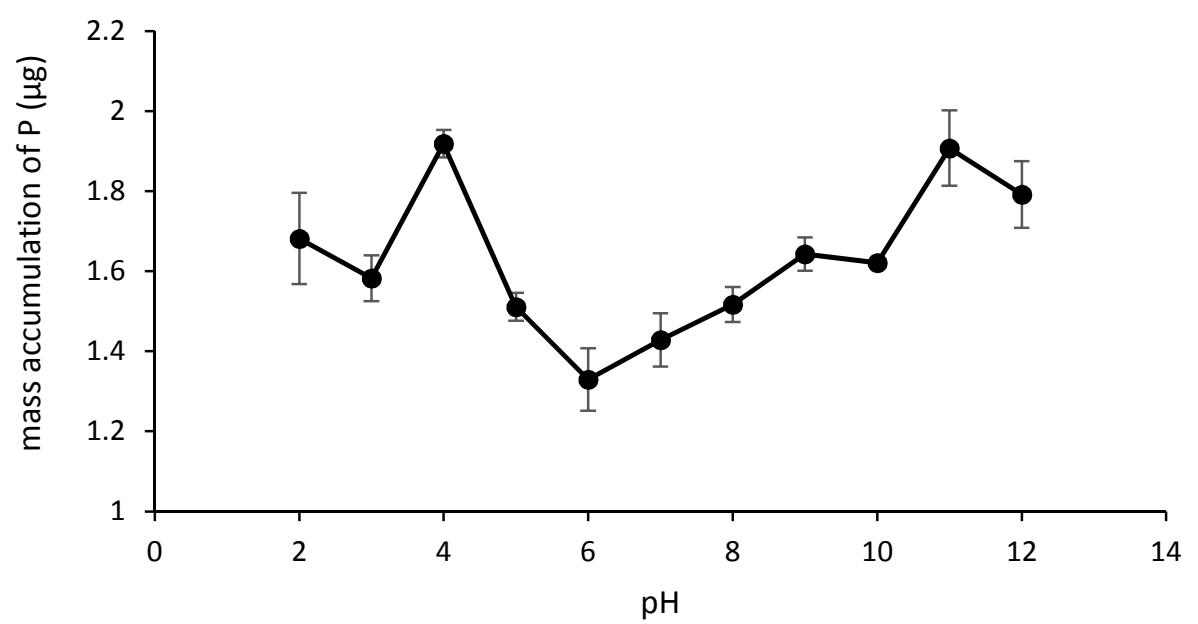

Fig.-4: Effect of pH Vs Accumulation of Phosphate in DGT Device

Table-3: Effect of Anions Interferences

\begin{tabular}{c|c|c|c}
\hline \multirow{2}{*}{ Anion Concentration $(\mu \mathrm{gL})$} & \multicolumn{3}{|c}{ Accumulation of Phosphate $(\mu \mathrm{g})$} \\
\cline { 2 - 4 } & $\mathrm{SO}_{4}{ }^{2-}$ & $\mathrm{NO}_{3}{ }^{-}$ & $\mathrm{CO}_{3}{ }^{2-}$ \\
\hline 0 & $4.5492 \pm 0.29$ & $4.5492 \pm 0.29$ & $4.5492 \pm 0.29$ \\
\hline 0.05 & $4.4864 \pm 0.28$ & $4.2866 \pm 0.30$ & $4.4799 \pm 0.20$ \\
\hline 0.10 & $4.0525 \pm 0.38$ & $3.2987 \pm 0.72$ & $4.4138 \pm 0.38$ \\
\hline 0.15 & $3.4872 \pm 1.8$ & $1.8569 \pm 0.65$ & $4.3588 \pm 0.12$ \\
\hline 0.20 & $3.4872 \pm 0.11$ & $1.8940 \pm 0.65$ & $4.2376 \pm 0.05$ \\
\hline 0.25 & $3.4072 \pm 0.25$ & $1.6085 \pm 1.27$ & $4.2046 \pm 0.04$ \\
\hline
\end{tabular}

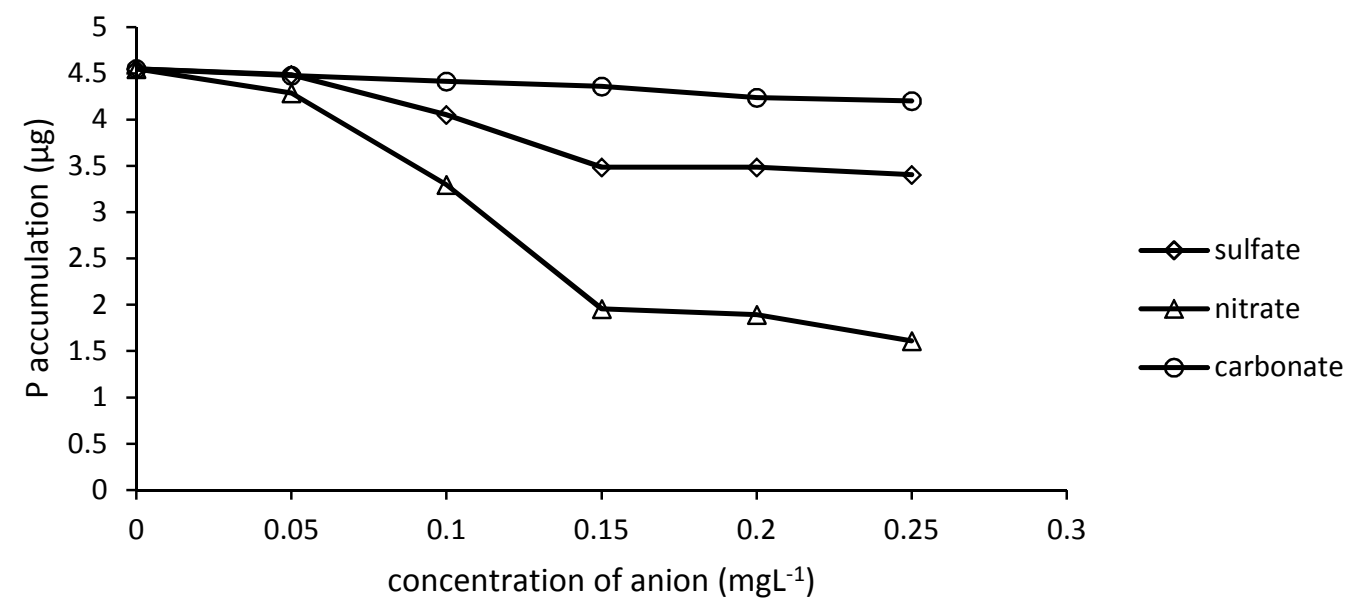

Fig.-5: Effect of Anion Interferences to DGT Unit

Based on Fig.-5 it can be seen the influence of sulfate ions can reduce the accumulated mass of phosphorus in DGT unit. The concentration of sulfate at $0.05 \mathrm{mgL}^{-1}$ was not significantly decreased in the absorption of phosphate in DGT. The interference of sulfate ion at $0.10 \mathrm{mgL}^{-1}$ can reduce phosphate accumulation in the binding gel from $4.5492 \mu \mathrm{g}$ to $4.0525 \mu \mathrm{g}$, the decrease of $11 \%$. The concentration of sulfate in $0.25 \mathrm{mgL}^{-1}$ indicated the decrease of phosphate accumulation to $3.4072 \mu \mathrm{g}$ with the efficiency of $25.10 \%$. In the nitrate ion interferences with a $0.05 \mathrm{mg} \mathrm{L}^{-1}$ significantly reduced the accumulation of 
phosphate mass was absorbed by DGT. The interference of nitrate ion at $0.10 \mathrm{mgL}^{-1}$ can reduce phosphate accumulation in the binding gel from $4.5492 \mu \mathrm{g}$ to $3.2987 \mu \mathrm{g}$ with the decrease of $27.48 \%$. The concentration of nitrate in $0.25 \mathrm{mgL}^{-1}$ indicated the decrease of phosphate accumulation to $1.6085 \mu \mathrm{g}$ with the efficiency of $64.64 \%$.Interferences of carbonate ions significantly do not convert the phosphate mass accumulation. The interference of carbonate ion at $0.05 \mathrm{mgL}^{-1}$ can reduce of phosphate accumulation in the binding gel from $4.5492 \mu \mathrm{g}$ to $4.4799 \mu \mathrm{g}$ with the decrease of $4.20 \%$. The concentration of carbonate in $0.25 \mathrm{mgL}^{-1}$ indicated the decrease of phosphate accumulation to $4.2046 \mu \mathrm{g}$ with the efficiency of $7.57 \%$. Generally, the carbonate ion was not influenced by the accumulation of phosphorus in the DGT unit.

\section{CONCLUSION}

Effect of $\mathrm{pH}$, anion interferences, and speciation of orthophosphate in the determination of phosphate by DGT technique was studied with ferrihydrite as the binding gel. DGT technique was the response of phosphate speciation as $\mathrm{H}_{2} \mathrm{PO}_{4}^{-}, \mathrm{HPO}_{4}{ }^{2-}, \mathrm{PO}_{4}{ }^{3-}$ in the range concentration of $0.2-1.0 \mathrm{mgL}^{-1}$ show the linear correlation. The DGT can response of phosphate with various $\mathrm{pH}$ at 2-12 and show the speciation of phosphate as $\mathrm{H}_{2} \mathrm{PO}_{4}{ }^{-}, \mathrm{HPO}_{4}{ }^{2-}$ and $\mathrm{PO}_{4}{ }^{3-}$. Anions interference were studied in this research including $\mathrm{SO}_{4}{ }^{2-}$, $\mathrm{NO}_{3}{ }^{-}$and $\mathrm{CO}_{3}{ }^{2-}$. Interferences of ion in a level of $0.05 \mathrm{mg} / \mathrm{L}$ were not the significant influence of accumulation of phosphate in the solution. The interference ion has influenced the accumulation of phosphate at the sulfate and nitrate concentration was $0.25 \mathrm{mgL}^{-1}$. The carbonate ion at 0.25 was not influenced by the accumulation of phosphate in solution.

\section{ACKNOWLEDGMENT}

We would like to thanks to Pusdiklat Industry, The Ministry of Industry, Indonesia who provided full support through all the stages of this study.

\section{REFERENCES}

1. S. Ding, Y. Wang, D. Xu, C. Zhu and C. Zhan, Environ. Sci. Technol., 47(14), 7821(2013), DOI: 10,1021/es 400192j

2. E. E. Burns, S. Comber, W. Blake, R. Goddard and L. Couldrick, Environ. Sci. Pollut. Res., 22(13), 9816 (2015), DOI: 10.1007/s11356-015-4109-3

3. Z. Feng, P. Zhu, H. Fan, S. Piao, L. Xu and T. Sun, Analytical Chemistry, 88(13), 6836(2016), DOI: 10.1021/acs.analchem.6B01392

4. S. S. Darade and N. N. Bandela, Rasayan Journal of Chemistry, 10(4), 1119(2017), DOI: 10.7324/RJC.2017.1041785

5. G. R. Deshpande, B. M. Rao, T. R. Sowjanya and N. Someswararao, Rasayan Journal of Chemistry, 2(1), 87(2009).

6. D. Murali and C. Rambabu, Rasayan Journal of Chemistry, 9(1), 67(2016).

7. C. V. Moorleghem, L. Six, F. Degryse, E. Smolders and R. Merckx, Analytical Chemistry, 83, 5317 (2011), DOI: 10.1021/ac200748e

8. W. W. Bennett, M. Arsic, D. T. Welsh and P. R. Teasdale, Environmental Science Processes \& Impacts, 18, 992(2016), DOI:101039/c6em00189k

9. W. Li, H. Zhao, P. R. Teasdale, R. John and S. Zhang, Analytica Chimica Acta, 464, 331(2002), DOI: 10.1016/S0003-2670(02)00492-0

10. H. Zhang, W. Davison, R. Gadi and T. Kobayashi, Analytica Chimica. Acta., 370, 29(1998), DOI: 10.1016/S0003-2670(98)00250-5

11. R. J. K. Dunn, P. R. Teasdale, J. Warnken and R. R. Schleich, Environ. Sci. Technol., 37, 2794(2003), DOI: $10.1021 / \mathrm{es} 026425 \mathrm{y}$

12. P. R. Teasdale, S. Hayward, and N. Davison, Analytical Chemistry, 71, 2186(1999), DOI: 10.1021/ac981329u

13. C. Naylor, W. Davison, M. Motelica-Heino, G. A. Van den Berg and L. M. Van den Heijdt, Science of the Total Environment, 328, 275(2004), DOI: 10.1016/j.scitotenv.2004.02.008

14. O. Clarisse and H. Hintelmann, Journal of Environmental Monitoring, 8, 1242(2006), DOI: 10.1039/b614560d 
RASĀYAN J. Chem.

Vol. 11 | No. 3 |1222 - 1228 | July - September | 2018

15. P. Divis, M. Kadlecova and B. Ouddane, Arch. Environ. Contam. Toxicol, 70(4), 700(2015), DOI: 10.1007/s00244-015-0231-y

16. C. Murdock, M. Kelly, L. Y. Chang, W. Davison and H. Zhang, Environ. Sci. Technol., 35, 4530(2001), DOI: 10.1021/es0100874

17. J. Drozdzak, M. Leermakers, Y. Gao and V. Phrommavanh, M. Descostes, Environmental Pollution, 214, 114(2016), DOI: 10.1016/j.envpol.2016.04.004

18. S. Ding, D. Xu Q. Sun H. Yin and C. Zhang, Environ.Sci.Tech, 44, 8169(2010), DOI: 10.1021/es1020873

19. S. Ding, F. Jia, D. Xu, Q. Sun, L. Zhang, C. Fan and C. Zhang, Environ. Sci. Tech., 45, 9680 (2011), DOI: $10.1021 /$ es202785p

20. W. Christel, C. Lemming, S. Mundus, S. Bruun, J. Magid and L. S. Jensen, Communication in Soil Science and Plant Analysis, 47(5), 1532 (2016), DOI: 10.1080/00103624.2016.1141920

21. C. Pichette, H. Zhang and S. Sauve, Aquaculture, 286, 198(2009), DOI: 10.1016/j.aquaculture.2008.09.025

22. M. Chen, S. Ding, L. Liu, D. Xu, M. Gong, H. Tang and C. Zhang, Science of the Total Environment, 542, 833(2016), DOI: 10.1016/j.scitotenv.2015.10.155

23. S. Mason, R. Hamon, H. Zhang and J. Anderson, Talanta, 74, 779(2008), DOI: 10.1016/j.talanta.2007.07.005

24. N. M. Menzies, B. Kusumo and P. W. Moody, Plant and Soil, 269, 1(2005), DOI: 10.1007/s11104004-1725-y

25. J.G. Panther, P. R. Teasdale, W. W. Bennett, D. T. Welsh and H. Zhao, Analytica Chimica Acta, 698, 20(2011), DOI: 10.1016/j.aca.2011.04.049

26. B. S. Cerozi and K. Fitzsimmons, Bioresource Technology, 219, 778(2016), DOI: 10.1016/j.biortech.2016.08.079

27. K. Karageorgiou, M. Paschalis and G. Anastassakis, Journal of Hazardous Material A139, 447(2007), DOI: 10.1016/j.jhazmat.2006.02.038

[RJC-3057/2018] 